\title{
Cost-effectiveness of a primary care based physical activity intervention in 45-74 year old men and women: a randomised controlled trial
}

\author{
W Stevens, M Hillsdon, M Thorogood, D McArdle
}

\begin{abstract}
Objective-To assess the cost-effectiveness of a primary care based intervention aimed at increasing levels of physical activity in inactive people aged 45-74. Methods-A total of 714 inactive people aged 45-74, taken from two west London general practices, were randomised into two groups. Intervention subjects were invited to a consultation with an exercise development officer, and offered a personalised 10 week programme to increase their level of regular physical activity, combining leisure centre and home based activities. Control subjects were sent information on local leisure centres. All subjects were followed up at eight months. Results-There was a net $10.6 \%(95 \%$ confidence interval 4.5 to $16.9 \%$ ) reduction in the proportion of people classified as sedentary in the intervention group compared with the control group, eight months after the intervention. The intervention group also reported an increase in the mean number of episodes of physical activity per week, as compared with the control group (an additional 1.52 episodes (95\% confidence interval 1.14 to 1.95$)$ ). The cost of moving a person out of the sedentary group was shown to be less than $£ 650$. The cost of moving someone to the now commonly recommended level was estimated at almost $£ 2500$.
\end{abstract}

Conclusions-Moderate physical activity can be successfully encouraged in previously sedentary men and women aged 45-74 through a primary care based intervention. The process of recruitment was the most important variable cost. A high uptake rate would maximise cost-effectiveness, and sensitivity analysis suggests that unit costs could be halved with a more effective recruitment strategy.

(Br F Sports Med 1998;32:236-241)

Keywords: physical activity promotion; primary care; middle aged

A recent report on physical activity and health by the US Surgeon General ${ }^{1}$ highlighted the main effects of physical activity on health and disease: lower total mortality rates and decreased risk of cardiovascular mortality, colon cancer, and non-insulin dependent diabetes. In addition, regular physical activity prevents or delays high blood pressure, reduces blood pressure in those with hypertension, and relieves the symptoms of depression and anxiety. A meta-analysis relating to physical activity in the prevention of coronary heart disease concluded that the relative risk of developing coronary heart disease in the least active compared with the most active was $1.9,^{2}$ similar to that of other risk factors such as smoking and hypertension.

It has been estimated that seven out of 10 men and eight out of 10 women take insufficient exercise to derive health benefits. ${ }^{3}$ Current recommendations ${ }^{4}$ are that adults should undertake either vigorous exercise three days a week for at least 20 minutes on each occasion or moderate intensity exercise five days a week for at least 30 minutes on each occasion. The first of these recommendations was derived mainly from the effect on cardiorespiratory endurance, but recently the benefits of less vigorous activity has become recognised, particularly for those who take little or no exercise. The recommendation of moderate activity is not meant to replace that for vigorous activity, but rather to complement it.

We report a randomised controlled trial of the effectiveness and cost effectiveness of a "Prescription for Exercise" scheme, based in primary care. The aim of the scheme was to increase levels of physical activity in inactive people aged $45-74$.

Primary care was chosen as the base for the scheme to ensure recruitment of a wide range of participants, as representative as possible of the British population. It has been estimated that almost $80 \%$ of people visit their doctor's surgery at least once a year. ${ }^{5}$

\section{Methods}

RECRUITMENT TO THE TRIAL

To identify currently inactive people, a self assessment questionnaire was sent to everyone on the surgery list aged 45-74. The three page questionnaire asked for basic demographic data (education, ethnicity, marital status, and economic activity) and a self assessment of the number of episodes of moderate and vigorous exercise, undertaken for at least 20 minutes, in the last four weeks. A list of activities was included to describe typically moderate and vigorous activity in terms of the activities of everyday life (see table 1). The questionnaire was adapted from a self administered seven day recall questionnaire used in other community

Table 1 Classification of moderate and vigorous activities

\begin{tabular}{ll}
\hline Moderate & Vigorous \\
\hline Brisk walking & Jogging/running \\
Heavy gardening & Competitive sports \\
Cycling for pleasure & Swimming lengths briskly \\
Heavy DIY & Climbing stairs \\
Swimming leisurely & Fast cycling \\
\hline
\end{tabular}




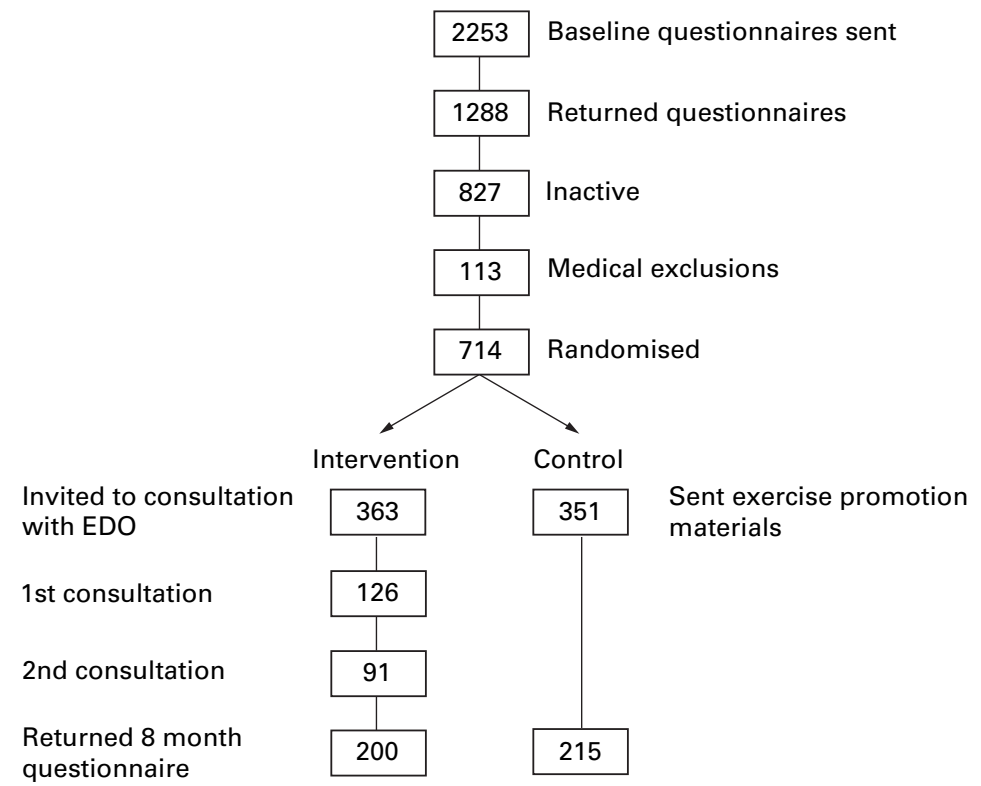

Figure 1 Study design. EDO, exercise development officer.

interventions. ${ }^{6}$ People who returned the completed physical activity questionnaires were classified into four levels of activity:

(a) sedentary-fewer than four 20 minute episodes of moderate or vigorous intensity activity in the previous four weeks;

(b) low intermediate-between four and eleven 20 minute episodes of moderate or vigorous intensity activity in the previous four weeks;

(c) high intermediate -12 or more 20 minute episodes of moderate or vigorous intensity activity in the previous four weeks, but less than either of the current recommendations;

(d) active-a minimum of either 2030 minute episodes of moderate intensity exercise or 1220 minute episodes of vigorous intensity exercise.

Subjects in the first three groups were regarded as inactive and eligible for randomisation into the trial, unless there was a medical reason for excluding them - for example, being registered disabled or having a diagnosis of heart disease. Eligible subjects were randomised using a random number generator to either the intervention or the control group.

NATURE OF THE INTERVENTION

The intervention subjects were sent a letter from their general practitioner inviting them to attend a consultation with an exercise development officer at a local leisure centre, which was centrally located within the ward. The consultation consisted of:

(a) a full explanation of the scheme;

(b) a medical/lifestyle questionnaire/consent form;

(c) physical measurements (height/weight/ body mass index);

(d) assessment of present activity level; (e) options available to be more physically active;

$(f)$ introduction to the physical activity diary.

An important aspect of the intervention was the lack of any preset goals or minimum achievements. Participants were made aware of the existing recommendations on physical activity and health, but they were neither expected nor pressured into achieving these standards. The options to become more physically active were designed to increase what the participants already did, rather than to try to force major changes to lifestyle.

The exercise programme lasted for 10 weeks, after which subjects were invited to return for a second consultation to discuss their progress.

Control subjects were sent information in the post on local leisure centres and health clubs along with information on physical activity and health. Figure 1 shows a summary of the trial.

OUTCOME EVALUATION

Eight months after randomisation, all subjects received a follow up questionnaire on self assessment of physical activity levels. The primary outcome of the trial was the change in reported levels of physical activity in the eight months between the completion of the baseline and follow up questionnaires. Subjects who did not complete the second questionnaire were assumed not to have changed their activity level.

\section{STATISTICAL ANALYSIS}

Statistical analysis was carried out using SPSS for Windows version 6.1. Differences between the intervention and control groups were tested using the comparison of means test and the $t$ test of significance. Unless otherwise stated, results are described on an "intention to treat" basis, with those subjects for whom there was no outcome measure being assigned to the activity level they reported at the start of the study.

ETHICS

Ethical approval was given by the Ealing, Hammersmith and Hounslow Health Authority Ethics Committee.

\section{Results}

RECRUITMENT

The baseline questionnaire was sent to 2253 people, and 1288 returned completed questionnaires, a response rate of $57 \%$. A comparison of the original general practice lists with the population returning the questionnaire showed that $63 \%$ of women returned a questionnaire compared with $46 \%$ of men. The response rate for subjects aged $65-74$ years was $64 \%$, while that for those aged 55-64 years was 54\%, and the youngest age group (45-54 years) had a response rate of $37 \%$. Of those who returned the questionnaire, $827(64 \%)$ were classified as not active-that is, in the lower three activity categories-but 113 of them were excluded from the study on medical grounds. A total of 714 subjects were randomised into the two trial groups. 
Table 2 Demographic and health related characteristics of the sample

\begin{tabular}{|c|c|c|}
\hline & $\begin{array}{l}\text { Intervention } \\
\text { group }(n=363)\end{array}$ & $\begin{array}{l}\text { Control } \\
\text { group }(n=351)\end{array}$ \\
\hline Percentage men & 40 & 44 \\
\hline Mean age (years) & 59.1 & 59.2 \\
\hline \multicolumn{3}{|l|}{ Age band $(\%)$} \\
\hline $45-54$ & 37 & 36 \\
\hline $55-64$ & 26 & 28 \\
\hline $65-74$ & 37 & 36 \\
\hline \multicolumn{3}{|l|}{ Body mass index (\%) } \\
\hline$<20$ & 4 & 5 \\
\hline $20-25$ & 50 & 53 \\
\hline$>25$ & 46 & 42 \\
\hline Current smokers ( $\%$ of total) & 18 & 17 \\
\hline \multicolumn{3}{|l|}{ Demographics } \\
\hline Economically active (\%) & 55 & 52 \\
\hline \multicolumn{3}{|l|}{ Ethnicity $(\%)$} \\
\hline White & 87 & 83 \\
\hline Black & 5 & 4 \\
\hline Asian & 4 & 8 \\
\hline Other & 4 & 5 \\
\hline \multicolumn{3}{|l|}{ Education (\%) } \\
\hline Degree/teaching & 28 & 30 \\
\hline A level & 12 & 12 \\
\hline O level/GCSE & 11 & 15 \\
\hline Other & 9 & 13 \\
\hline None & 36 & 32 \\
\hline \multicolumn{3}{|l|}{ Physical activity level group (\%) } \\
\hline Sedentary & 55 & 51 \\
\hline Low intermediate & 42 & 45 \\
\hline High intermediate & 3 & 4 \\
\hline Active & 0 & 0 \\
\hline
\end{tabular}

Table 3 Mean number of occasions of physical activity in the four weeks before follow up

\begin{tabular}{lllll}
\hline & Intervention & Control & Difference & $\begin{array}{l}\text { 95\% Confidence } \\
\text { interval }\end{array}$ \\
\hline Moderate physical activity & 5.09 & 3.64 & 1.45 & 1.03 to 1.74 \\
Vigorous physical activity & 0.86 & 0.78 & 0.08 & 0.01 to 0.30 \\
All episodes & 5.95 & 4.43 & 1.52 & 1.14 to 1.95 \\
\hline
\end{tabular}

RANDOMISATION

There were 363 subjects randomised to receive an invitation for a consultation with an exercise development officer (the intervention group) and 351 subjects randomised to receive an information pack on leisure centre facilities in the post (the control group). Table 2 gives details on baseline characteristics of the intervention and control groups, and shows that the groups were broadly similar, with no significant differences.

\section{UPTAKE OF THE INTERVENTION EXERCISE}

PROGRAMME

Of the 363 subjects randomised to the intervention group, only $126(35 \%)$ attended the first consultation with the exercise development officer. Ninety one subjects (25\%) returned for the second consultation at the end of the 10 week exercise programme.

PHYSICAL ACTIVITY LEVELS AT FOLLOW UP Table 3 shows the mean number of occasions of physical activity in the previous four weeks reported by the intervention and control groups at eight months follow up. It must be

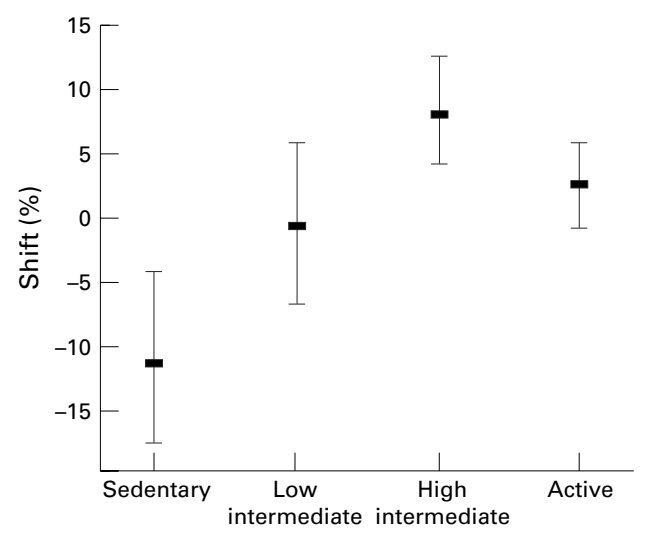

Figure 2 Change in the proportion of subjects in each physical activity level group, relative to the control, between baseline and eight month follow up, with $95 \%$ confidence intervals.

noted that all measures of physical activity are self reported and as such must be open to the usual levels of scrutiny. Both moderate and total occasions of physical activity were significantly greater in the intervention group. Vigorous activity was also higher in the intervention group but did not reach significance.

Table 4 shows leisure centre usage and total physical activity in subjects classified as sedentary and low intermediate at baseline (no high intermediate subjects completed all parts of the trial). Subjects who were more active at baseline were more likely to have used the leisure centre at some time during the four weeks before the first consultation while both groups increased their usage during the eight months. Table 4 also shows that at follow up both groups were exercising away from the leisure centre at least as often as they were exercising at it.

Figure 2 shows the percentage change in activity categories at eight months in both intervention and control subjects. There is a reduction in the number of subjects in the lowest two activity categories and an increase in the highest two categories in the intervention group, with similar but smaller changes in the control group. Figure 3 shows the eight month activity level of subjects by their baseline level of physical activity. Subjects not available at follow up ( $n=163)$ were assumed not to have changed. Overall, 79 subjects moved into a higher level of physical activity with only 17 moving down. The biggest changes were from sedentary to low intermediate $(14 \%)$ and low intermediate to high intermediate $(14 \%)$. Few subjects moved into the active group.

CosTs

Recruitment costs were calculated using a top down approach. All resources were costed unless

Table 4 Leisure centre usage and total activity by baseline level of physical activity in intervention subjects completing all stages of the study

\begin{tabular}{llllll}
\hline & $\begin{array}{l}\text { Percentage of } \\
\text { patients reporting } \\
\text { using a leisure } \\
\text { centre at 1st } \\
\text { consultation }\end{array}$ & $\begin{array}{l}\text { Mean number of } \\
\text { visits to leisure } \\
\text { centre in 4 weeks } \\
\text { before baseline }\end{array}$ & $\begin{array}{l}\text { Percentage of } \\
\text { patients reporting } \\
\text { using a leisure } \\
\text { centre at 8 month } \\
\text { follow up }\end{array}$ & $\begin{array}{l}\text { Mean number of } \\
\text { visits to leisure } \\
\text { centre in 4 weeks } \\
\text { before follow up }\end{array}$ & $\begin{array}{l}\text { Mean occasions } \\
\text { of physical } \\
\text { activity in } 4 \\
\text { weeks before } \\
\text { follow up }\end{array}$ \\
Baseline activity status & 4 & 2.5 & 16 & 4.1 & 7.9 \\
\hline Sedentary $(\mathrm{n}=55)$ & 25 & 33 & 4.6 & 9.6 \\
Low intermediate (n=36) & 25 & & & \\
\hline
\end{tabular}




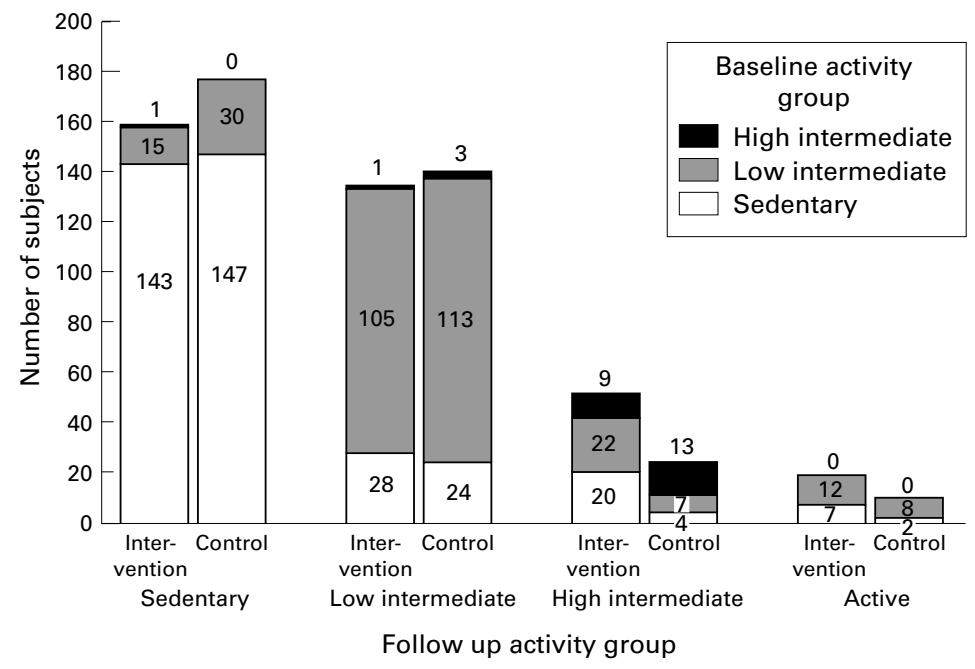

Figure 3 Number of subjects in each physical group at follow up by baseline group (intervention $n=363$; control $n=351$ ).

Table 5 Costs of recruitment by stage

\begin{tabular}{llll}
\hline & $\begin{array}{l}\text { Stage 1 } \\
\text { (didentification } \\
\text { as inactive) }\end{array}$ & $\begin{array}{l}\text { Stage 2 } \\
\text { (invited for } \\
\text { consultation) }\end{array}$ & $\begin{array}{l}\text { Stage 3 } \\
\text { (completed } \\
\text { programme) }\end{array}$ \\
\hline Population & 2253 & 363 & 363 \\
Response & 1288 & 126 & 91 \\
Response rate (\%) & 57 & 35 & 25 \\
Postage & $£ 985$ & $£ 227$ & $£ 30$ \\
$\begin{array}{l}\text { Stationery } \\
\text { Labour }\end{array}$ & $£ 580$ & $£ 145$ & $£ 315$ \\
$\quad \begin{array}{l}\text { Admininistration } \\
\text { EDO }\end{array}$ & $£ 952$ & $£ 224$ & $£ 840$ \\
Equipment & - & $£ 984$ & $£ 18040$ \\
Total costs & $£ 2517$ & $£ 1580$ & $£ 4819$ \\
\hline
\end{tabular}

${ }^{\star}$ Labour costs include institution costs as well as wage costs; EDO, Exercise Development Officer.

they were deemed to be used for research purposes only. For costing of the baseline recruitment (stage 1), the costs of questionnaire design and production, mailing, and follow up of those people who did not reply first time were included. However, only one third of the cost of processing the data from the questionnaires was included, as about two thirds of the data were collected for research purposes, unrelated to carrying out the intervention.

Table 5 shows the participation and completion rates at each stage together with the costs of each stage. Stage 1 was the recruitment stage, involving the mailing, completion, and analysis of the baseline questionnaires, stage 2 was the process of invitation to an exercise consultation, and stage 3 was the intervention itself.

COST-EFFECTIVENESS

We used three measures of effectiveness in calculating cost-effectiveness. Firstly, we considered the cost of inducing one sedentary person to undertake more physical activity, the main intended outcome of the trial. This is measured by the net decrease in the proportion of sedentary people after the intervention net of the same decrease seen in the control group and gives a cost per person of $£ 623$. Secondly, we considered the cost of moving someone who is active, but below the minimum required level, to that minimum level. This is calculated as the
Table 6 Cost-effectiveness of the intervention

\begin{tabular}{|c|c|c|c|}
\hline & $\begin{array}{l}\text { Reduction in } \\
\text { no of sedentary } \\
\text { people }\end{array}$ & $\begin{array}{l}\text { Increase in no } \\
\text { of people who } \\
\text { are active }\end{array}$ & $\begin{array}{l}\text { Movement into } \\
\text { higher level of } \\
\text { physical activity }\end{array}$ \\
\hline Total cost & $£ 24043$ & $£ 24043$ & $£ 24043$ \\
\hline Gross shift (\%) & 11.2 & 5.8 & 21 \\
\hline Net shift (\%) & 10.6 & 2.7 & 20 \\
\hline People equivalent ${ }^{\star}$ & 38 & 10 & 73 \\
\hline Cost per person & $£ 623$ & $£ 2498$ & $£ 327$ \\
\hline
\end{tabular}

proportionate increase net of the control group for the number attaining the top group classification. This was achieved at a cost of just under $£ 2500$ per person. Thirdly, we considered the cost of achieving any increase in an individual's level of physical activity. The cost of this was $£ 327$ for movement into a higher activity group or less than $£ 200$ for an absolute increase in physical activity. Table 6 gives a summary of the results.

\section{SENSITIVITY ANALYSIS}

Table 7 shows the breakdown of medium term fixed and variable costs for the intervention by stage. Most costs, such as the salary of the exercise development officer and the equipment, were fixed. The main factor that would affect the cost-effectiveness of the intervention is the take up rate. In this trial, there was a planned capacity of up to 363 attendees in the exercise programme, but a response of just $35 \%$, leaving underused resources. Because this was a relatively small scale trial, the administrative work (posting, data entry, and appointment management) was carried out by the exercise development officer. On a larger scale, this work could be performed by a clerk at lower cost. The equipment costed for the project was underutilised, but also has a working life beyond the duration of the trial. Most of the equipment has a capital life of between five and 10 years and therefore annual equivalent cost was used to ensure a more realistic programme cost.

Sensitivity analysis shows no sizeable change to unit costs from the changes in definition of capital and administration costs, but table 8 gives details of the effect on unit costs when the stage one and two response rates are changed. The range of testing took the stage 1 response rate up to $74 \%$ and the stage 2 response rate up to $68 \%$, rates that have actually been achieved in another continuing trial by one of us $(\mathrm{M} \mathrm{H})$. Variation in recruitment rates had a profound effect on unit cost. With a combination of a $74 \%$ response rate in stage 1 and a $68 \%$ response rate in stage 2 , unit costs were less than half of that recorded during this intervention, assuming similar levels of adherence to the programme in all subjects. The response rate at stage 2 had the biggest effect on this. Recruitment strategy will be an important aspect of the cost-effectiveness of any exercise promotion intervention.

Table 7 Costs of intervention by stage

\begin{tabular}{llll}
\hline & $\begin{array}{l}\text { Stage 1 } \\
\text { (identification } \\
\text { as inactive) }\end{array}$ & $\begin{array}{l}\text { Stage 2 } \\
\text { (made available } \\
\text { for consultation) }\end{array}$ & $\begin{array}{l}\text { Stage 3 } \\
\text { (completed } \\
\text { programme) }\end{array}$ \\
\hline Total costs $(£)$ & 2517 & 1579 & 24043 \\
Fixed costs $(£)$ & 952 & 1208 & 23698 \\
Variable costs $(£)$ & 1565 & 371 & 345 \\
\hline
\end{tabular}


Table 8 Sensitivity analysis and cost consequences $(\mathcal{A})$

\begin{tabular}{lllll}
\hline & $\begin{array}{l}\text { Cost per complete } \\
\text { programme } \\
\text { attender }\end{array}$ & $\begin{array}{l}\text { Cost per } \\
\text { sedentary person } \\
\text { reduced }\end{array}$ & $\begin{array}{l}\text { Cost per person } \\
\text { classified as } \\
\text { active }\end{array}$ & $\begin{array}{l}\text { Cost per } \\
\text { person moved } \\
\text { up a group }\end{array}$ \\
\hline $\begin{array}{l}\text { Current programme } \\
\text { Response rate at stage } 1\end{array}$ & 279 & 623 & 2498 & 327 \\
$\quad 60 \%$ & 252 & 588 & 2295 & 310 \\
$65 \%$ & 236 & 550 & 2145 & 290 \\
$70 \%$ & 222 & 517 & 2018 & 273 \\
$74 \%$ & 212 & 494 & 1928 & 260 \\
Response rate at stage 2 & 236 & 550 & & \\
$40 \%$ & 197 & 460 & 179 & 290 \\
$50 \%$ & 172 & 402 & 1566 & 242 \\
$60 \%$ & 158 & 368 & 1437 & 194 \\
$68 \%$ & 182 & 424 & 1652 & 223 \\
With stage 1 response rate at & $74 \%$, response rate at stage 2 & 1381 & 187 \\
$40 \%$ & 152 & 354 & 1206 & 163 \\
$50 \%$ & 133 & 309 & 1107 & 150 \\
$60 \%$ & 122 & 284 & & \\
$68 \%$ & & & \\
\hline
\end{tabular}

\section{Discussion}

This study is the largest United Kingdom based randomised controlled trial to date evaluating physical activity promotion in primary care. It provides encouragement for the continuing development of a primary care based physical activity strategy.

One difference between this study and other "Prescription for Exercise" trials reported in the literature is that in this trial general practitioners were not directly involved in either the recruitment of subjects or the intervention itself. An exercise specialist was used at both stages. Other trials have found it difficult to recruit using general practitioners, because the competing demands on the general practitioner's time lead to the activity intervention taking a low priority, with low levels of recruitment and a focus on patients at lower risk of health problems (mainly younger women who want to lose weight). ${ }^{78}$ If physical activity promotion is going to make an impact on population health, then the intervention needs to be made available and attractive to those with the most health benefit to gain. ${ }^{9}$ This study also showed a higher proportion of women attending the first stage of the intervention. Different methods for recruiting men to such interventions need to be identified.

One possible method of increasing the priority of physical activity promotion is to have a dedicated member of staff. The person used in this study was an exercise specialist with relevant qualifications. What remains unclear is whether or not this level of expertise would necessarily be required in a non-research intervention. Also, this study only used one exercise development officer and therefore it is unclear as to whether any particular characteristics of this person influenced the outcomes of the study, limiting the generalisability of the results. It is difficult to assess the impact of this "therapist effect", because of the lack of similar trials for comparison. Future interventions could be run by existing primary care staff such as a community physiotherapist or a practice nurse. This would involve additional training, and its associated costs, but this may be offset by lower overall wage costs.

Although the proportion of subjects who made use of the leisure centre increased during the course of the study, most physical activity was undertaken away from the centre. Environmental efforts focused on increasing opportunities for activities not requiring attendance at a leisure centre, such as walking, may have a greater impact on the prevalence of inactivity.

The cost-effectiveness analysis showed the importance of the success in recruitment. A high take up of the offered advice enables better management of the expensive resources, particularly the personnel, and even a small difference in take up rates at each stage could have sizeable effects on the cost of achieving outcomes.

We identified two areas where a change in the organisation of the trial might have improved response.

(1) The letter of invitation specifically mentioned exercise and could have been interpreted as being critical of the patient's current less than active lifestyle. A copy of the letter is shown in the appendix. People are usually reluctant to come to any consultation if they expect to be "told off". The method of invitation should be designed to be as non-judgemental as possible. We have experienced more success in recruiting in another continuing trial with a more neutral invitation letter.

(2) The letter of invitation to a consultation did not include a set consultation time. It asked for the recipient of the letter to take the initiative in arranging an appointment. Again, a higher response has been achieved when an appointment time is given and the recipient is asked to cancel or rearrange it if not convenient.

More research into optimal methods of recruiting participants for all primary care based health promotion initiatives is needed.

This study has shown that it is possible to reduce the proportion of sedentary people in this population, but it is more difficult to achieve the current recommended levels of activity. We have seen an increase in the level of physical activity for subjects in each of the baseline activity levels. Small gradual changes in activity behaviour seem to be more achievable than major ones, and an increase in moderate intensity physical activity has proved easier to achieve than an increase in vigorous intensity activity. The lack of objective measures to corroborate self reported physical activity in this study should be considered when interpreting these findings.

Some commentators have argued that any increase in the level of physical activity among older people, especially those who are sedentary, will be of benefit to their health. ${ }^{410}$ The definition of positive outcomes in physical activity interventions should be broad enough to include small gains in those at greatest risk, rather than setting a threshold below which any activity is seen as being of no value. We should concentrate on changes in lifestyle that are achievable, because a small gain for a lot of people can represent a large gain for the health of the population. 
CONCLUSIONS

This study has shown that it is possible to increase levels of physical activity at a moderate intensity in men and women aged 45-74 through a primary care based intervention. The results of the cost-effectiveness analysis show that the recruitment process was the most important aspect of the intervention. To maximise cost-effectiveness it is important to have a high take up rate. Sensitivity analysis suggests that unit costs can be halved with a better recruitment strategy.

We would like to thank Pat Mahoney for the original idea, the doctors and patients at both the Avenue Crescent Practice and Southfields Medical Centre as well as Ealing Leisure Services for their cooperation and assistance with this project. This trial was supported by West London Health Promotion Agency through a grant awarded by North Thames NHS Executive T are all supported by the Health Gain Project, funded jointly $\mathrm{T}$ are all supported by the Health Gain Project, funded jointly by North

1 US Department of Health and Human Services. Physical activity and health: a report of the Surgeon General. Atlanta GA: US Department of Health and Human Services, Centers for Disease Control and Prevention, National Center for Chronic Disease Prevention and Health Promotion, 1996.

2 Berlin JA, Colditz GA. A meta-analysis of physical activity in the prevention of coronary heart disease. Am $\mathcal{F}$ Epidemiol 1990;132:639-46.

3 Allied Dunbar National Fitness Survey. Main findings. London: Sports Council and Health Education Authority, 1992

4 Pate RR, Pratt M, Blair SN, et al. Physical activity and public health: a recommendation from the Center for Disease Control and Prevention and the American College of Sports Medicine. $¥ A M A$ 1995;273:402-7.

5 Royal College of General Practitioners. Morbidity statistics from general practice: fourth national study. 1991-1992. from general practice: fourth national study. 1991-1992. 6 Blair SN. How to assess exercise habits and physical fitness. In: Matarazzo JD, Weiss SM, Herd SA, et al, eds. Behaviour In: Matarazzo JD, Weiss SM, Herd SA, et al, eds. Behaviour
health: a handbook of health enhancement and disease prevenhealth: a handbook of health enha
7 Fielder H, Shorney S, Wright D. Lesson from a pilot study on prescribing exercise. Health Education fournal 1995; 54: on prescribin

8 Lord LC, Green F. Exercise on prescription: does it work? Health Education fournal 1995;54:453-64.

9 Naidoo B, Thorogood M, McPherson K, et al. Modelling the effects of increased physical activity on coronary heart disease in England and Wales. I Epidemiol Community Health 1997;51:144-50.

10 Haskell WL. Health consequences of physical activity: understanding and challenges regarding dose response. Med Sci Sports Exerc 1994;26:649-60.

\section{Appendix: Invitation to meet with exercise specialist \\ Dear Sir/madam,}

Thank you for taking the time to return your Physical Activity Questionnaire. The information has been invaluable in helping to provide a picture of the health needs of our local population.

It has been well established that physical inactivity is a major factor contributing to coronary heart disease.

I have arranged a consultation with an exercise specialist for you. He will advise you on how to incorporate a greater degree of physical activity, helping you to maintain an active and enjoyable lifestyle. The consultation will look at what kind of physical activity you would get the most benefit from. It will take into account your personal circumstances and what facilities and activities are available to you.

To fix an appointment please fill in the enclosed card and post it in the reply paid envelope.

Yours sincerely

Dr X

\section{Commentary}

This paper shows the modest effectiveness of a prescription for exercise scheme based in primary care. In two urban practices, 2253 patients were sent questionnaires, based on a response rate of $57 \%$, and $64 \%$ were found to be sedentary. After randomisation to consultation with an exercise development officer, eight months later $204 / 363=56 \%$ were active in the exercise prescription group compared with $174 / 351=49 \%$ in the control group (odds ratio $=1.30 ; 95 \%$ confidence interval $=1.27$ to 1.34 ). While this improvement is encouraging, the fact that only $12 \%$ of the sedentary individuals at risk actually would have benefitted from such a programme limits its effectiveness as a useful strategy. This limited penetration of physical activity to the at risk population is especially important since disabled patients and those with coronary heart disease, who would both benefit from increased physical activity, were excluded from this study.

The principal advantage of addressing physical activity in the primary care setting is to build on the continuity of care over time that primary care practitioners provide and the ability of the primary care provider to motivate patients at teachable moments. The strategy presented in this report does not incorporate these aspects of primary care. The cost analysis is revealing and demonstrates the high cost of making people active and relatively low cost of increasing activity levels to higher levels in those with intermediate levels of physical activity. The lessons learned from this trial and others ${ }^{12}$ in primary care will in time lead to effective physical activity counselling. Ultimately, I am confident that a cost-effective method that utilises both physician and health care team members and appropriate social and economic reinforcements will be found.

C B EATON

Pawtucket, Rhode Island

1 The Green Prescription Study: a randomised controlled trial of exercise prescription in general practice. Am f Public Health (in

2 Calfas KJ, Long BJ, Dallis JF, et al. A controlled trial of physician counselling to promote the adoption of physical activity. Prev Med 1996;25:225-33.
Melfas KJ, Long BJ, Da.tis 